\title{
Audit of Orthopaedic Audits in an English Teaching Hospital: Are We Closing the Loop?
}

\author{
H.J. Iqbal ${ }^{*}$ and P. Pidikiti
}

St. Helens and Knowsley Teaching Hospitals NHS Trust, Warrington Road, Prescot, Merseyside, L35 5DR, UK

\begin{abstract}
Background: Clinical audit is an important tool to improve patient care and outcomes in health service. A significant proportion of time and economic resources are spent on activities related to clinical audit. Completion of audit cycle is essential to confirm the improvements in healthcare delivery. We aimed this study to evaluate audits carried out within trauma and orthopaedic unit of a teaching hospital over the last 4 years, and establish the proportions which were re-audited as per recommendations.

Methods: Data was collected from records of the clinical audit department. All orthopaedic audit projects from 2005 to 2009 were included in this study. The projects were divided in to local, regional and national audits. Data regarding audit lead clinicians, completion and presentation of projects, recommendations and re-audits was recorded.

Results: Out of 61 audits commenced during last four years, 19.7\% (12) were abandoned, 72.1\% (44) were presented and $8.2 \%$ (5) were still ongoing. The audit cycle was completed in only $29 \%$ (13) projects.

Conclusion: Change of junior doctors every $4 \sim 6$ months is related to fewer re-audits. Active involvement by supervising consultant, reallocation of the project after one trainee has finished, and full support of audit department may increase the ratio of completion of audit cycles, thereby improving the patient care.
\end{abstract}

Keywords: Audit of audits, orthopaedic audits, quality of care, audit cycle.

\section{INTRODUCTION}

Delivery of high quality patient care is essential in modern NHS (National Health Service). Clinical audit is an important tool to improve and safeguard patient care. National Institute for Clinical Excellence (NICE) published principles for best practice in clinical audit [1] which defined clinical audit as "a quality improvement process that seeks to improve patient care and outcomes through systematic review of care against explicit criteria and the implementation of change. Aspects of structure, process, and outcomes of care are selected and systematically evaluated against explicit criteria. Where indicated, changes are implemented at an individual, team, or service level and further monitoring is used to confirm improvement in healthcare delivery". A substantial sum of funding and time has been spent establishing audit practice in the NHS [2]. It has become a key component of clinical governance framework [3]. Recently there has been a move from "optional" clinical activity to more "obligatory" approach. All clinical staff is required to actively take part in clinical audit. Concerns have also been raised on loss of clinical time and money on auditing too many events without clear goals $[2,4]$.

A good clinical audit can provide objective evidence of improvement of quality of patient care and outcomes. This is only possible through completing audit cycle [1]. There are

*Address correspondence to this author at the Trauma and Orthopaedics, St. Helens and Knowsley Teaching Hospitals NHS Trust, Warrington Road, Prescot, Merseyside, L35 5DR, UK;

Tel: 0151254 1616; Fax: 01744646681; E-mail: hafjavaid@yahoo.com multiple studies showing substantial improvements through completion of audit cycle [5-7]. According to above mentioned definition, an audit project will be regarded as completed only after further monitoring (re-audit) has been performed following implementation of improvement. Therefore, $100 \%$ of the projects should complete an audit cycle. Without completion of an audit cycle, a sound evidence of quality improvement in health care can not be provided. However, there have been reports of poor proportion of completion of audit cycle across the NHS [8$10]$. We aimed this study to analyse the last 4 years clinical audits performed in trauma and orthopaedic unit of local teaching hospital to evaluate the completion of audit cycle.

\section{MATERIALS AND METHODOLOGY}

This was a retrospective review of all clinical audits performed in trauma and orthopaedic department of local teaching hospital from Apr 2005 to Apr 2009. Data was collected from the records of clinical audit department. We divided these projects into local, regional and national. We analysed the overall audit proposals, projects abandoned, leading clinicians, audits completed and the ratio of reaudits. We also investigated into the reasons for premature abandoning of some of the audit projects and potential reasons for not completing the audit cycle.

In our hospital, like many others in the NHS, there is a dedicated clinical audit department which overlooks all the audit projects being performed in the hospital. It provides support for designing the data collection tools, collection of case notes and database design/analysis. We also have an audit facilitator in our department who is an orthopaedic consultant with special interests in audit and research. Every 


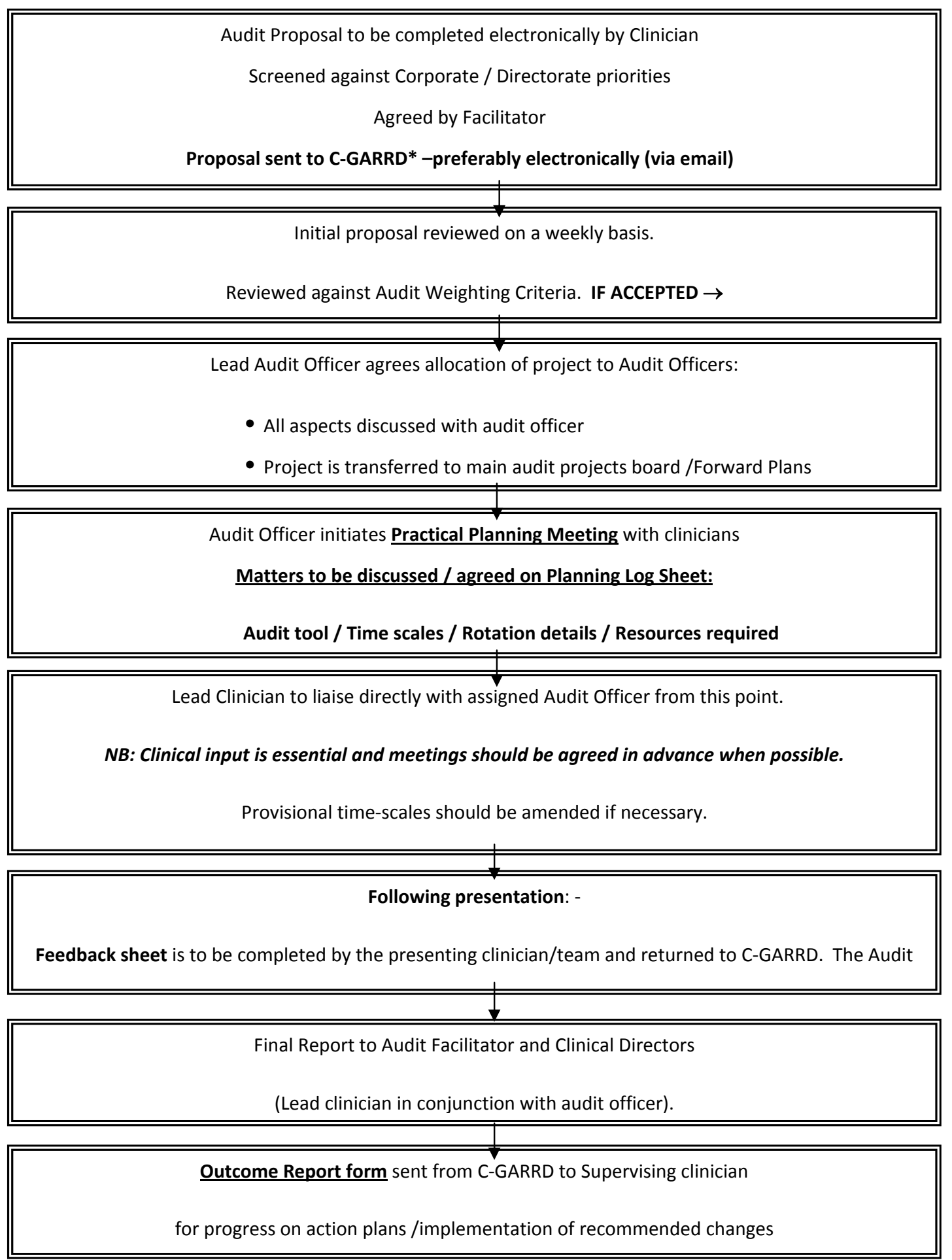

*Clinical governance, audit, research resource department. (C-GARRD)

Fig. (1). Process Flow Chart for Registration and Accessing Support of Audit Projects at our Hospital.

clinical audit project starts with defining a topic, based on clinical issues in delivery of high quality care to patients. The audit lead is responsible for literature search to define standard criteria, against which, the findings of the study will be compared. All of this is written on an official form which needs to be approved by the facilitator before submission to the audit department.
Fig. (1) presents the flow chart of the audit process in our hospital. The audit gets started only after approval from the audit department. After completion and presentation of audit findings in the departmental or hospital audit meeting, a feedback form is filled by the audit lead, explaining the implementation of recommended changes and plans for future re-audit to complete audit cycle. This is stored in the 


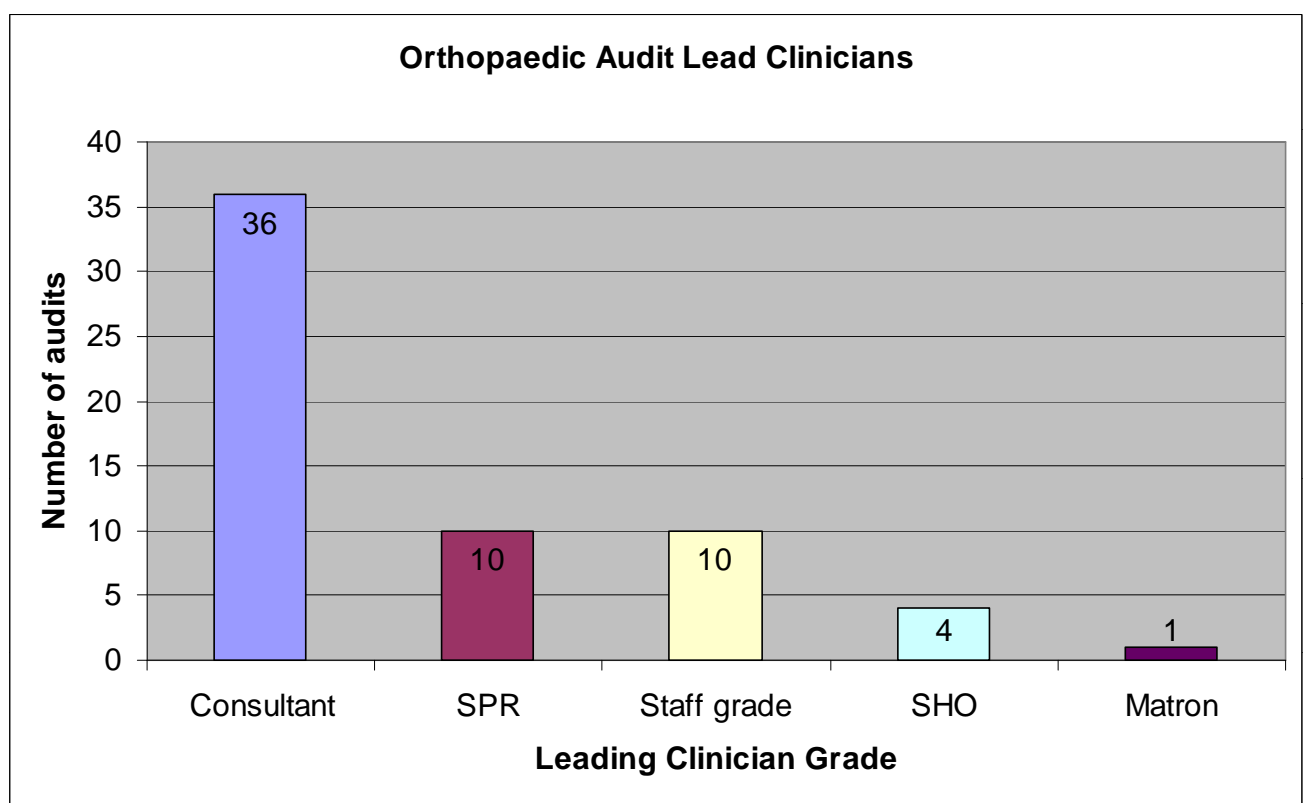

Fig (2). The leading clinicians and audit projects.

audit department data base for future reference. All of this process is time consuming but essential to monitor and streamline the audit activity in the hospital.

\section{RESULTS}

On the whole, 61 audits were commenced over the 4 years period. Most of these (59) were local, one project was part of the regional audit (Management of patients with Neck of Femur fractures in Trusts across the North West of England) and another audit was a part of national audit (National Comparative Audit of the use of Blood in patients undergoing Hip replacement). A consultant was either a leading clinician or was a supervising person in 59\% (36) of the audits. SpR (Specialist Registrar) and staff grade surgeon each were the leaders of $16 \%$ projects. An SHO (Senior House Officer) alone was leading clinician in $7 \%$ (4) projects (Fig. 2).

Overall, a variety of topics were covered in these audit projects. Almost $20 \%$ projects were related to management of patients with hip fractures. This is consistent with practice in other trauma and orthopaedic units [9]. Other favourite topics were related to outcome after arthroplasty, infection and fracture management. Table $\mathbf{1}$ provides a summary of the areas covered and examples of important audit projects.

Out of 61 audit projects, 12 (19.7\%) were abandoned, 44 $(72.1 \%)$ were completed and presented in audit meetings and $5(8.2 \%)$ audits were still ongoing. Only $13(29 \%)$ projects had audit cycle completed by re-audits. Table 2 shows year by year audit performance in trauma and orthopaedic unit of local teaching hospital. Table 3 illustrates the reasons why some of the audits were abandoned.

\section{DISCUSSION}

Clinical audit has now become an essential part of clinical governance. A well conducted audit provides an objective way to review the quality of care, within a supportive and developmental approach. In trauma and orthopaedic unit of this teaching hospital, almost 15 audits were commenced every year over the last 4 years. Approximately $20 \%$ of the audits were abandoned due to either poor planning or the junior doctor, who was conducting the audit, moved to other hospital. Of the other $80 \%$ projects, $72 \%$ were completed and presented in the departmental meetings while $8 \%$ were still ongoing. This ratio of completion is much better than the other similar published studies $[8,10,11]$. Just completion of audit does not provide guarantee to improve the health care. It is the process of re-audit after implementation of change which ensures that standards of clinical care are continuously improved and maintained. Surprisingly, only $29 \%$ of the projects completed the audit cycle by process of re-audit. Gnanalingham et al. [8] and Guryel et al. [11] found even worse results in their studies. In their studies, $24 \%$ and $20 \%$ of the audits respectively, completed the audit cycle.

There have been concerns about audit being waste of money and time [4]. This could be true for those audit projects which are started without appropriate planning and either get abandoned or do not generate any action plan to improve the quality of care. Appropriate planning is therefore essential for any audit project. This involves carefully selecting a topic, relative literature search, definition of standard criteria, involvement of supervising consultant and signed undertaking by the audit lead to complete the project or handover to someone else in case they leave the department before completion of the audit.

Although audit is considered as an integral part of junior doctors training in NHS, issues of inadequate supervision and support have also been raised in some studies [12, 13]. Guryel et al. [11] found that if an audit was led by a named consultant or a nurse, there was a greater chance of audit cycle being completed. In our study, $61 \%$ of the projects were supervised by named consultant or a nurse. In spite of this, the percentage of re-audits has not changed significantly. Reallocation of the project to new trainee after one trainee has finished could lead to improve the ratio of audit cycle being completed. Active involvement of audit 
Table 1. Summary of Audit Projects and Areas Covered (Total = 61 Audits)

\begin{tabular}{|c|c|}
\hline Audit Topics and Examples of Salient Projects & $\%$ (No.) \\
\hline $\begin{array}{ll}\text { - } & \text { Neck of Femur Fractures } \\
\text { - } & \text { IV fluids management } \\
\text { - } & \text { Post operative complications } \\
\text { - } & \text { Delays in physiotherapy and mobilisation } \\
\text { - } & \text { Cemented versus uncemented hemiarthroplasty } \\
\text { - } & \text { Hip fracture pathways audit }\end{array}$ & $19.7 \%(12)$ \\
\hline $\begin{array}{ll}\text { - } & \text { Outcome Following Surgical Procedures } \\
\text { - } & \text { Hotal hip replacement } \\
\text { - } & \text { Total knee replacement } \\
\text { - } & \text { ACL reconstruction } \\
\text { - } & \text { Hallux rigidus surgery (Hallufix Plates) }\end{array}$ & $13.1 \%(8)$ \\
\hline 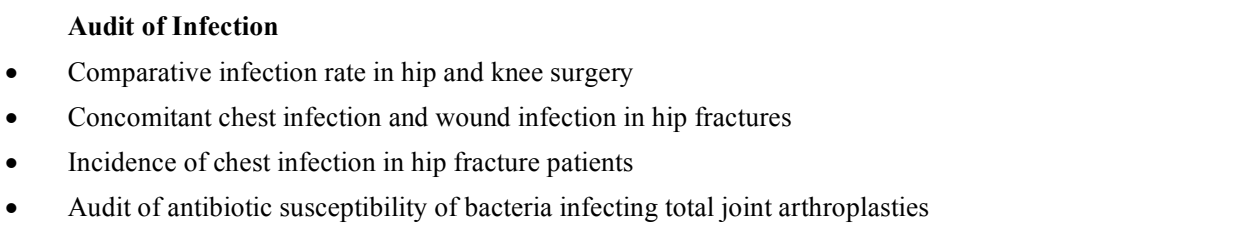 & $6.5 \%(4)$ \\
\hline 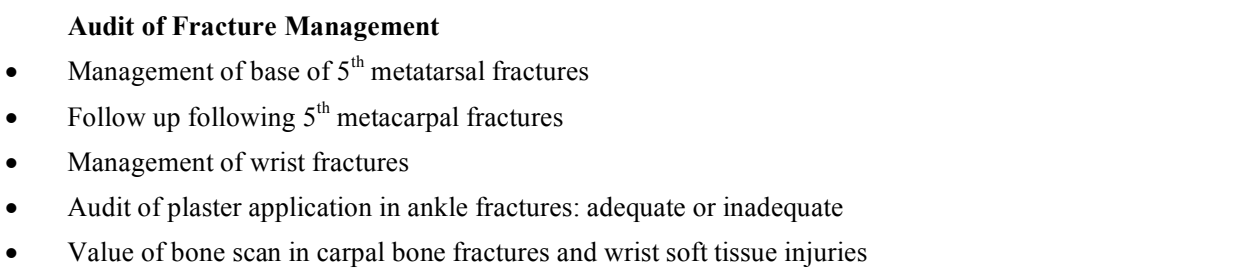 & $9.8 \%(6)$ \\
\hline Audit of Record Keeping in Orthopaedics & $9.8 \%(6)$ \\
\hline $\begin{array}{ll}\text { - } & \text { Revision Hip Surgery Audit } \\
\text { - } & \text { Reasons for revision hip surgery } \\
\text { - } & \text { Reasons for hip dislocation } \\
& \text { Rev revision hip surgery }\end{array}$ & $4.9 \%(3)$ \\
\hline $\begin{array}{ll} & \text { Audit of Incidence of DVT } \\
\text { - } & \text { Following hip and knee arthroplasty } \\
\text { - } & \text { Following ankle fractures }\end{array}$ & $3.2 \%(2)$ \\
\hline Audit of the Requirement of Blood Transfusion After Primary Total Hip and Knee Arthroplasty & $6.5 \%(4)$ \\
\hline 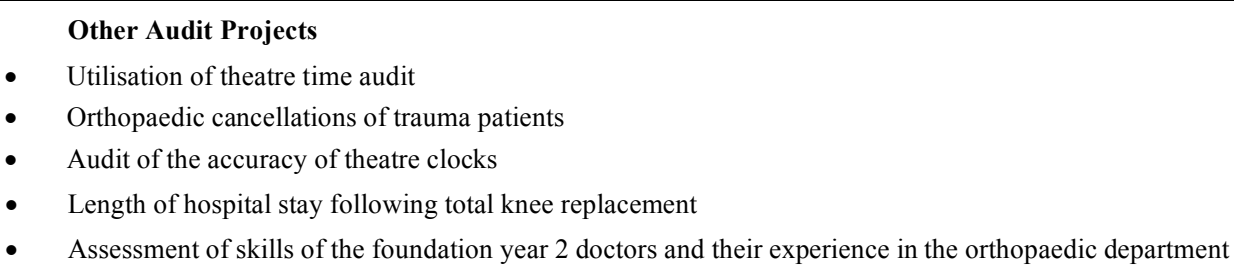 & $26.2 \%(16)$ \\
\hline
\end{tabular}

department and supervising consultants is very important in this regard. A system of reminder, e.g. an automatic email warning to the supervising consultant regarding re-audit dates may be helpful to improve re-audit ratios.

A uniform quality of care throughout the NHS is the aim of health department. National and regional audits could ensure that high standards of health care are being maintained across the country. However, we found that this particular trauma and orthopaedic unit has been part of only one regional and one national audit over the last 4 years. More resources and coordination between different hospitals is required for successfully conducting the regional and national audits. Table 4 presents some recommendations to improve the overall audit process.

In conclusion the overall percentage of completion of audit cycle is low. Good preparation, adequate resources, 
Table 2. Yearly Audit Performance

\begin{tabular}{|l|c|c|c|c|c|c|}
\hline \multicolumn{1}{|c|}{ Audit Year } & $\mathbf{2 0 0 5 / 0 6}$ & $\mathbf{2 0 0 6 / 0 7}$ & $\mathbf{2 0 0 7 / 0 8}$ & $\mathbf{2 0 0 8 / 0 9}$ & Overall & \% \\
\hline \hline Total audit proposals & 15 & 16 & 17 & 13 & 61 & $100 \%$ \\
\hline Number abandoned & 4 & 4 & 3 & 1 & 12 & $19.7 \%$ \\
\hline Number still live/ongoing & & & & 5 & 5 & $8.2 \%$ \\
\hline Number presented & 11 & 12 & 14 & 7 & 44 & $72.1 \%$ \\
\hline Total Re-audits completed & 3 & 4 & 2 & 4 & 13 & $29.54 \%$ \\
\hline
\end{tabular}

active involvement and supervision by the senior members of the staff and audit department are paramount to successful completion of the audit cycle which can ensure improvement in the quality of care.

\section{Table 3. Audits Abandoned and Reasons}

\begin{tabular}{|l|c|}
\hline \multicolumn{1}{|c|}{ Reasons for Abandoning } & No of Audits \\
\hline \hline No Reason recorded & 7 \\
\hline Clinician left trust & 2 \\
\hline Unable to get sufficient sample size & 1 \\
\hline Unable to identify relevant patients & 1 \\
\hline Audit not started & 1 \\
\hline Total & 12 \\
\hline
\end{tabular}

\section{Table 4. Recommendations}

- Full preparation before start of the audit project

- Signed undertaking by audit lead to complete the project and handover to next person if leaves hospital before completion.

- Nominate a person to follow the project when one trainee is moved to other hospital

- Automatic generation of email reminder to the assigned supervisor regarding re-audit date

- Regularly review the quality and the effect of the projects

\section{ACKNOWLEDGEMENT}

We are grateful to the audit department, especially Victoria Peers for helping us to complete this project.

\section{ABBREVIATIONS}

$\mathrm{F} 2=$ Foundation year 2 doctor

$\mathrm{SHO}=$ Senior House Officer

$\mathrm{SpR}=$ Specialist Registrar

NHS $=$ National Health Service

NOF $=$ Neck of femur

\section{REFERENCES}

[1] National Institute for Clinical Excellence. Principles for best practice in clinical audit. Edited, Oxford, Radcliffe Medical Press, 2002.

[2] Earnshaw JJ. Auditing audit: the cost of the emperor's new clothes. Br J Hosp Med 1997; 58(5): 189-92.

[3] NHS Executive. Clinical Governance: Quality in the new NHS Edited, London, Department of health, 1999. Available at: http://www.dh.gov.uk/prod_consum_dh/groups/dh_digitalassets/@ dh/@en/documents/digitalasset/dh_4012043.pdf

[4] Sellu D. Time to audit audit. BMJ 1996; 312: 128-9.

[5] Cohen SN, Lanigan SW. Audit cycle of documentation in laser hair removal. Lasers Med Sci 2005; 20(2): 87-8.

[6] Freeman C, Todd C, Camilleri-Ferrante C, et al. Quality improvement for patients with hip fracture: experience from a multi-site audit. Qual Saf Health Care 2002; 11(3): 239-45.

[7] Merle V, Moret L, Pidhorz L, et al. Does comparison of performance lead to better care? A pilot observational study in patients admitted for hip fracture in three French public hospitals. Int J Qual Health Care 2009; 21(5): 321-9.

[8] Janaki GMG, Gnanalingham K. An audit of audits: are we completing the cycle? J R Soc Med 2001; 94: 288-9.

[9] Kurup HV, McMurtrie A, Sarasin S. Auditing the audits: are we missing the point? J Eval Clin Pract 2007; 13(5): 829-30.

[10] Tabandeh H, Thompson GM. Auditing ophthalmology audits. Eye 1995; 9(6 Suppl): 1-5.

[11] Guryel E, Acton K, Patel S. Auditing orthopaedic audit. Ann R Coll Surg Engl 2008; 90(8): 675-8.

[12] McCarthy MJ, Byrne GJ. Surgical audit: the junior doctors' viewpoint. J R Coll Surg Edinb 1997; 42(5): 317-8.

[13] Nettleton J, Ireland A. Junior doctors' views on clinical audit--has anything changed? Int J Health Care Qual Assur Inc Leadersh Health Serv 2000; 13(6-7): 245-53. 